\title{
AQP4e-Based Orthogonal Arrays Regulate Rapid Cell Volume Changes in Astrocytes
}

\author{
Marjeta Lisjak, ${ }^{1 \star}$ Maja Potokar, ${ }^{1,2 *}$ (Doštjan Rituper, ${ }^{1}$ - Jernej Jorgačevski, ${ }^{1,2}$ and Robert Zorec ${ }^{1,2}$ \\ ${ }^{1}$ Laboratory of Neuroendocrinology-Molecular Cell Physiology, Institute of Pathophysiology, Faculty of Medicine, University of Ljubljana, 1000 Ljubljana, \\ Slovenia, and ${ }^{2}$ Celica Biomedical, 1000 Ljubljana, Slovenia
}

Water channel aquaporin 4 (AQP4) plays a key role in the regulation of water homeostasis in the brain. It is predominantly expressed in astrocytes at the blood- brain and blood-liquor interfaces. Although several AQP4 isoforms have been identified in the mammalian brain, two, $\mathrm{AQP4a}(\mathrm{M1})$ and $\mathrm{AQP} 4 \mathrm{c}(\mathrm{M} 23)$, have been confirmed to cluster into plasma membrane supramolecular structures, termed orthogonal arrays of particles (OAPs) and to enhance water transport through the plasma membrane. However, the role of the newly described water-conductive mammalian isoform AQP4e is unknown. Here, the dynamics of AQP4e aggregation into OAPs and its role in the regulation of astrocyte water homeostasis have been studied. Using super-resolution structured illumination, atomic force, and confocal microscopies, the results revealed that, in female rat astrocytes, $\mathrm{QQP} 4 \mathrm{e}$ isoform colocalizes with $\mathrm{OAPs}$, affecting its structural dynamics. In hypoosmotic conditions, which elicit cell edema, OAP formation was considerably enhanced by overexpressed AQP4e. Moreover, the kinetics of the cell swelling and of the regulatory volume decrease was faster in astrocytes overexpressing $\mathrm{AQP} 4 \mathrm{e}$ compared with untransfected controls. Furthermore, the increase in maximal cell volume elicited by hypoosmotic stimulation was significantly smaller in AQP4e-overexpressing astrocytes. For the first time, this study demonstrates an active role of $\mathrm{AQP} 4 \mathrm{e}$ in the regulation of $\mathrm{OAP}$ structural dynamics and in water homeostasis.

Key words: aquaporin 4; astrocytes; atomic force microscopy; glia; orthogonal arrays of particles; structured illumination microscopy

Significance Statement

Water channel aquaporin 4 (AQP4) plays a key role in the regulation of water homeostasis in the brain. To date, only AQP4a and $\mathrm{AQP} 4 \mathrm{c}$ isoforms have been confirmed to enhance water transport through plasmalemma and to cluster into orthogonal arrays of particles (OAPs). We here studied the dynamics, aggregation, and role in the regulation of astrocyte water homeostasis of the newly described water-conductive mammalian isoform AQP4e. Our main findings are as follows: brain edema mimicking hypoosmotic conditions stimulates the formation of new 0APs with larger diameters, due to the incorporation of additional cytoplasmic $\mathrm{AQP} 4$ channels and the redistribution of $\mathrm{AQP} 4$ channels of the existing OAPs; and AQP4e affects the dynamics of cell swelling and regulatory volume decrease in astrocytes exposed to hypoosmotic conditions.

\section{Introduction}

Aquaporin 4 (AQP4), the most abundant water channel in the CNS, selectively transports water molecules (Jung et al., 1994;

Received March 22, 2017; revised July 31, 2017; accepted Sept. 23, 2017.

Author contributions: M.P., J.J., and R.Z. designed research;M.L., B.R., and J.J. performed research; R.Z. contributed unpublished reagents/analytic tools; M.L. and B.R. analyzed data; M.L., M.P., B.R., J.J., and R.Z. wrote the paper.

This work was supported by Grants P3 0310, J3 6790, and J3 7605 from the Research Agency of Slovenia. We thank Professor Antonio Frigeri (University of Bari, Bari, Italy) and Professor Vanda A. Lennon (Mayo Clinic, Rochester, NY) for providing NMO-IgG antibodies, and Professor Ole Petter Ottersen for the generous gift of AQP4e-GFP plasmid.

${ }^{*} M$.L. and M.P. contributed equally to this work

The authors declare no competing financial interests.

Correspondence should be addressed to either Robert Zorec or Jernej Jorgačevski, Laboratory of Neuroendocrinology-Molecular Cell Physiology, Institute of Pathophysiology, Faculty of Medicine, University of Ljubljana, Zaloška 4, 1000 Ljubljana, Slovenia, E-mail: robert.zorec@mf.uni-lj.si or jernej.jorgacevski@mf.uni-lj.si. DOI:10.1523/JNEUROSCI.0776-17.2017

Copyright $\odot 2017$ the authors $\quad 0270-6474 / 17 / 3710748-09 \$ 15.00 / 0$
King et al., 2004; Tani et al., 2009; Nagelhus and Ottersen, 2013; Badaut et al., 2014). It is expressed in ependymal cells lining the ventricles, in the end feet of astrocytes of the perivessel and subpial areas of the brain, and in astrocyte plasma membranes that face synapses (Frigeri et al., 1995; Nielsen et al., 1997; Rash et al., 1998; Nagelhus et al., 2004). The abundant presence of AQP4 in the plasma membrane of astrocytes associated with brain-liquor or brain-blood interfaces is important for the regulation of brain water homeostasis, the primary role of AQP4 in the brain (Agre et al., 1995; Nielsen et al., 1997; Manley et al., 2000; King et al., 2004; Verkman et al., 2006; Haj-Yasein et al., 2011; Nagelhus and Ottersen, 2013; Badaut et al., 2014).

Several water-permeant isoforms of AQP4 have been described in mammals. In addition to the classic and the most studied, AQP4a (M1) and AQP4c (M23), the AQP4e (Mz) isoform has been identified in rat, mouse, pig, and human brains (Hasegawa et al., 1994; Jung et al., 1994; Yang et al., 1995; Moe et 


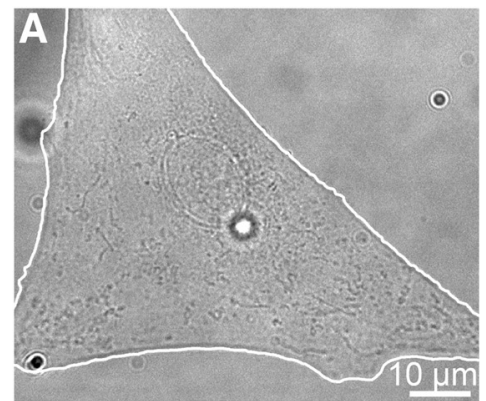

C

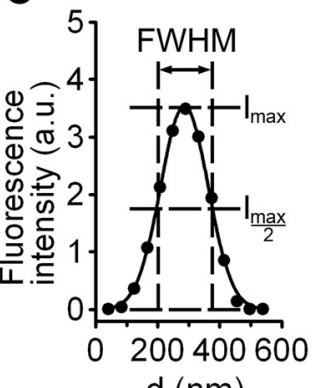

$\mathrm{d}(\mathrm{nm})$

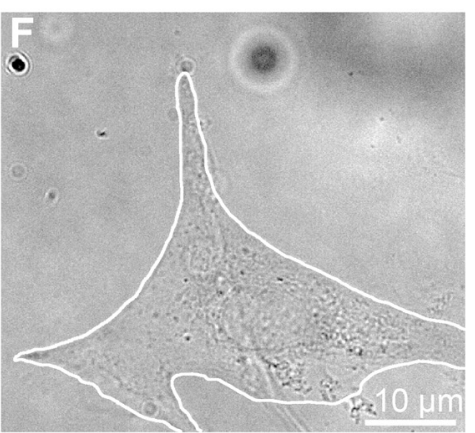

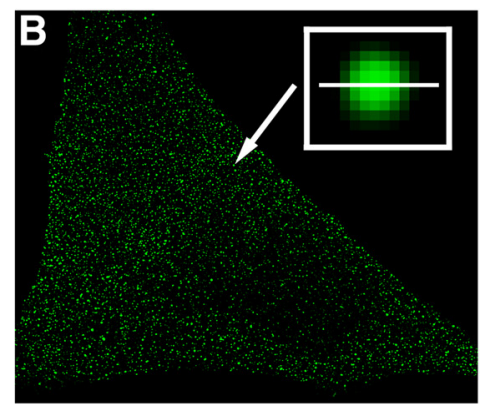

E
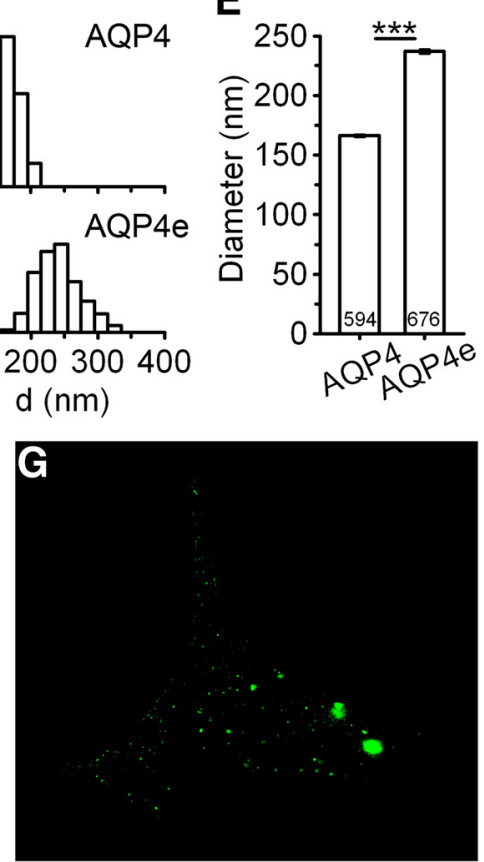

Figure 1. Measurements of $A Q P 4$ microdomains (MiDs) in astrocytes. $A$, The DIC image of a cultured rat astrocyte. The white line delineates the cell. Scale bar, $\boldsymbol{A}$ (for $\boldsymbol{A}, \boldsymbol{B}), 10 \mu \mathrm{m}$. $\boldsymbol{B}$, Fluorescence micrograph of the same astrocyte as in $\boldsymbol{A}$, recorded with SIM, showing a punctiform pattern of MiDs labeled with AQP4 antibodies that labeled intracellular and plasma membrane AQP4 channels (AQP4 MiD). The arrow denotes an MiD (197 nm in diameter) enlarged in the framed inset. C, MiD diameters were determined by measuring the full-width at half-maximum (FWHM) of the fluorescence intensity profile along the equatorial line (the length of the line, shown in $\boldsymbol{B}$, is $500 \mathrm{~nm}$ ) in the horizontal and vertical directions (here only the horizontal direction is displayed). D, Histograms show diameter distributions for AQP4 MiDs (594 MiDs from 7 cells) and AQP4e MiDs (intracellular and plasma membrane MiDs in astrocytes expressing the recombinant AQP4e; $676 \mathrm{MiDs}$ from 8 cells). $\boldsymbol{E}$, AQP4e-expressing MiDs were on average wider $(237 \pm 1 \mathrm{~nm})$ than AQP4-labeled MiDs (166 $\pm 1 \mathrm{~nm}) .{ }^{* *} p<0.001 . \boldsymbol{F}, \boldsymbol{G}$, The DIC image of a cultured rat astrocyte and corresponding fluorescent micrograph displaying recombinant AQP4e. Scale bar, $\boldsymbol{F}($ for $\boldsymbol{F}, \boldsymbol{G}), 10 \mu \mathrm{m}$.

al., 2008; Rossi et al., 2011; Sørbø et al., 2012). It is well established that AQP4a and AQP4c are present in the plasma membrane where they aggregate into orthogonal arrays of particles (OAPs; i.e., supramolecular structures that may also be important for water permeability through the plasma membrane; Hasegawa et al., 1994; Jung et al., 1994; Yang et al., 1995, 1996; Rash et al., 1998; Crane and Verkman, 2009; Crane et al., 2010).

Localization of the recently identified AQP4e isoform in the plasma membrane has been confirmed in HeLa cell lines, human malignant glioblastoma cell lines, rat brain lysates, and primary cultured rat astrocytes (Moe et al., 2008; Sorbo et al., 2008; Rossi et al., 2011; Potokar et al., 2013). Moreover, the abundance of AQP4e in the plasma membrane dynamically responds to the extracellular milieu, as was shown in rat astrocytes exposed to conditions mimicking hypoosmotic challenge and cerebral edema, which is characteristic for several pathologies, including stroke, tumor, infection, hydrocephalus, and traumatic brain injury (Papadopoulos et al., 2004; Verkman et al., 2006; Nase et al., 2008; Wolburg et al., 2012; Potokar et al., 2013). Biochemical evidence suggests that AQP4e also clusters into OAPs, as was shown in cells that do not natively express AQP4 (Sorbo et al., 2008; Strand et al., 2009; Rossi et al., 2011). However, the properties of AQP4e aggregation dynamics into the plasma membrane OAPs and its role in the water transport at the cellular level are completely unknown.

In this report studying astrocytes, we address two important issues. First, we investigated whether AQP4e affects OAP dynamics (their abundance and size) in isoosmotic and hypoosmotic conditions. Second, we evaluated whether the AQP4e isoform plays a role in the regulation of cell volume in real time.

The main findings are as follows: hypoosmotic conditions stimulate the formation of new OAPs; the overexpression of AQP4e increases the formation of additional OAPs, and in hypoosmotic conditions an additional doubling was recorded; enlargement of the diameter of OAPs after hypoosmotic stimulation indicates the incorporation of additional cytoplasmic AQP4 channels and/or the redistribution of AQP4 channels of the existing OAPs; and the AQP4e isoform affects the dynamics of cell swelling and regulatory volume decrease (RVD) in astrocytes exposed to hypoosmotic conditions.

\section{Materials and Methods}

\section{Cell cultures}

Astrocyte cultures were prepared by standard procedure from cortices isolated from 3-d-old female Wistar rats (Potokar et al., 2013) and maintained in growth medium (high-glucose DMEM containing $10 \%$ fetal bovine serum), 1 mM sodium pyruvate, $2 \mathrm{~mm}$ glutamine, and 25 $\mu \mathrm{g} / \mathrm{ml}$ penicillin/streptomycin) at $37^{\circ} \mathrm{C}, 95 \%$ air/5\% $\mathrm{CO}_{2}$. For structured illumination microscopy (SIM) and confocal microscopy experiments, astrocytes were plated onto 22mm-diameter glass coverslips coated with $1 \%$ poly-L-lysine adhesive solution. For atomic force microscopy (AFM) experiments, cells were plated onto poly-L-lysine-coated WPI FD35 FluoroDish cell culture dishes. Chemicals for maintaining cell cultures and for experiments were purchased from Sigma-Aldrich. All reagents were of the highest purity available.

\section{Aquaporin 4 labeling}

Aquaporin 4 microdomains. Immunolabeling by AQP4 antibody or expressing recombinant $\mathrm{AQP} 4 \mathrm{e}$ isoform in astrocytes results in a punctiform fluorescent signal representing clusters of AQP4 channels (Fig. 1). These punctiform AQP4 assemblages were termed microdomains (MiDs), where the distance between individual AQP4s is $<100 \mathrm{~nm}$ (the resolution limit of the SIM system; Fig. 1). MiDs were labeled either with antibodies in permeabilized cells or were identified by a fluorescent signal of pAQP4e-GFP (green fluorescent protein; AQP4e) in transfected cells. However, these two approaches do not discriminate between the intracellular and plasma membrane pools of MiDs. For immunolabeling of 
MiDs, we used commercially available primary antibodies against AQP4 (rabbit polyclonal antibody against intracellular amino acids 244-323 of the C-terminal domain, 1:400; Santa Cruz Biotechnology; and rabbit polyclonal antibody against intracellular amino acids 249-323 of the C-terminal domain, 1:300; Alomone Labs). Briefly, astrocytes were washed in PBS, fixed, and permeabilized in $4 \%$ formaldehyde solution [15 min, room temperature (RT)], incubated in blocking buffer [3\% bovine serum albumin (BSA) and 10\% goat serum in PBS] to prevent background staining $\left(1 \mathrm{~h}, 37^{\circ} \mathrm{C}\right)$, and labeled with primary antibodies against AQP4 (overnight, $4^{\circ} \mathrm{C}$ ) following by goat anti-rabbit IgG secondary antibodies conjugated to fluorescent dye Alexa Fluor 488 (1:600, 45 $\min , 37^{\circ} \mathrm{C}$; Invitrogen). Samples were mounted onto glass slides with Slowfade Gold antifade reagent (Invitrogen).

Recombinant AQP4e isoform was overexpressed by transfecting cells with pAQP4e-GFP encoding the fusion protein between AQP4e and GFP (a gift from O.P. Ottersen's laboratory, University of Oslo, Oslo, Norway). Cell transfection was performed with Lipofectamine LTX transfecting reagent (Invitrogen) or with FuGENE 6 (Promega) in live cells, according to the manufacturer instructions.

Orthogonal arrays of particles. OAPs in nonpermeabilized cells were labeled with neuromyelitis optica (NMO) IgG antibodies that recognize the extracellular AQP4 epitope, do not affect OAP size, and do not induce AQP4 internalization (Lennon et al., 2004, 2005; Hiroaki et al., 2006; Nicchia et al., 2009; Ratelade et al., 2011; Rossi et al., 2012a,b). These antibodies are present in the serum of patients with NMO disorder where they selectively bind to AQP4 at the abluminal face of microvessels and meninges in CNS tissues recognizing the extracellular domains of AQP4 in the plasma membrane (Cheng et al., 1997; Takumi et al., 1998; Iorio et al., 2013).

Labeling with NMO-IgG antibodies was performed in a manner similar to that described previously (Potokar et al., 2008). Briefly, the cells were washed in PBS, incubated in 3\% BSA in PBS (3 min, RT) and labeled with NMO-IgGs (1:200, $10 \mathrm{~min}, \mathrm{RT}$; a gift from A. Frigeri, University of Bari, Bari, Italy) or heat inactivated $\left(30 \mathrm{~min}, 56^{\circ} \mathrm{C}\right)$ NMO-IgG serum (1:200, 10 min, RT; a gift from Vanda A. Lennon, Mayo Clinic, Rochester, MN), followed by goat anti-human IgG secondary antibodies conjugated to fluorescent dye Alexa Fluor 546 (1:600, 20 min, RT; Invitrogen).

Hypoosmotic stimulation. Control samples were treated with isoosmolar extracellular solution (300 mOsm) consisting of the following (in $\mathrm{mm}$ ): $130 \mathrm{NaCl}, 5 \mathrm{KCl}, 2 \mathrm{CaCl}_{2}, 1 \mathrm{MgCl}_{2}, 10$ D-glucose, and $10 \mathrm{HEPES}$, $\mathrm{pH}$ 7.2. Hypoosmotic conditions were obtained by reducing the osmolarity of the isoosmolar medium from 300 to $200 \mathrm{mOsm}$ by the application of $100 \mathrm{mOsm}$ solution consisting of the following (in $\mathrm{mm}$ ): $30 \mathrm{NaCl}$, $5 \mathrm{KCl}, 2 \mathrm{CaCl}_{2}, 1 \mathrm{MgCl}_{2}, 10$ D-glucose, and 10 HEPES, pH 7.2.

\section{Measurements of cell volume changes}

Live untransfected astrocytes and astrocytes transfected with pAQP4eGFP were loaded with cytosolic sulforhodamine 101 dye (SR101; $10 \mu \mathrm{M}$; Invitrogen) for $15 \mathrm{~min}$ at $37^{\circ} \mathrm{C}$ and exposed to either isoosmotic or hypoosmotic conditions ( $200 \mathrm{mOsm})$. Images were recorded with a laser confocal microscope (LSM 780, Zeiss) using an oil-immersion objective (40X/numerical aperture 1.3). AQP4e-GFP transfected cells were confirmed by Ar laser excitation ( $488 \mathrm{~nm}$ ), and emitted light was filtered with a bandpass filter at $493-553 \mathrm{~nm}$. SR101 was excited by a DPSS laser $(561 \mathrm{~nm})$, and the emission light was filtered with a bandpass filter at 567-649 nm. Time-series images were recorded with a DPSS laser $(561 \mathrm{~nm})$ every $2 \mathrm{~s}$ for $30 \mathrm{~s}$ before and $90 \mathrm{~s}$ after hypotonic stimulation. Changes in the fluorescence intensity of SR101 were analyzed with Zen 2010 software (Zeiss) using the mean region of interest tool, which calculates the average fluorescence intensity. Detailed analysis and fitting of the data were performed in SigmaPlot version 11.0 (SYSTAT). Changes in the fluorescence intensity of the cytosolic fluorescent probe were used as an indicator of changes in the cell volume (Benfenati et al., 2011; Mola et al., 2016).

Structured illumination microscopy: the imaging and the analysis Recordings were performed with a Zeiss ELYRA PS.1 super-resolution microscope, with an oil-immersion Plan-Apochromat $63 \times / 1.4$ differential interference contrast (DIC) objective (Zeiss). Fluorescent dyes were illuminated with 488 and $561 \mathrm{~nm}$ laser beams, and the emitted fluores- cence was collected through the bandpass emission filters (495-560 nm and $570-650 \mathrm{~nm}$, respectively); 500-nm-thick $Z$ stacks were acquired with an EMCCD camera (Andor iXon 885, Andor Technology) and analyzed in ZEN 2011 software (Zeiss). MiD, OAP diameters, and fluorescence intensities were measured as shown in Figure $1, B$ and $C$. If, in a given $z$-plane, the MiD was out of focus (we compared the fluorescence intensity of each $\mathrm{MiD}$ in at least three different $z$-planes), we performed the measurement in the focal plane (maximal fluorescence intensity, minimum full-width at half-maximum). We calculated the fraction of plasma membrane-located MiDs as the percentage of OAP versus all MiDs in a given $z$-plane.

\section{Atomic force microscopy measurements and cell volume determination}

Nanowizard II (JPK Instruments) was used in conjunction with an inverted optical microscope (Observer.Z1, Zeiss). Images were acquired in intermittent-contact mode at a $0.4 \mathrm{~Hz}$ line rate and $128 \times 128$ pixel lateral resolution. We used thermally stabilized HYDRA6V-100NG (AppNano) V-shaped cantilevers with a spring constant of $0.29 \pm 0.01$ $\mathrm{N} / \mathrm{m}$, measured using the thermal noise method (Hutter and Bechhoefer, 1993). Free cantilever oscillating amplitude and the imaging set point were maintained throughout the experiment, ensuring comparable sample indentation, and stimulus was applied as described in Figure 5. Cell volume was calculated using the zero basis volume calculation protocol (built into Gwyddion; Nečas and Klapetek, 2012) in the region of interest (i.e., the cell) of the leveled AFM images. Volume changes were normalized to the initial cell volume and are expressed as a relative change.

\section{Statistics}

Statistical analysis was performed in SigmaPlot (SYSTAT). Results are presented as the mean \pm SEM. First, a normality test was performed on the data, then statistical significance was evaluated using ANOVA with the Holm-Sidak post hoc test for normally distributed data and the MannWhitney test or ANOVA on ranks with the Kruskal-Wallis or Dunn's post hoc test for non-normally distributed data. We considered significance with the following symbols: ${ }^{*} p<0.05,{ }^{* *} p<0.01$, and ${ }^{* *} p<0.001$.

\section{Results}

\section{AQP4 and AQP4e microdomains in rat astrocytes are variable} in size

The AQP4 water channel has diverse subcellular distribution in isolated astrocytes; ranging from the plasma membrane to endosomes, lysosomes, and secretory vesicles (Nicchia et al., 2008; Potokar et al., 2013). When AQP4 channels are fluorescently labeled in isolated astrocytes, a dispersed punctiform pattern reminiscent of vesicular structures is observed (Fig. 1A,B), as described previously (Nicchia et al., 2008; Potokar et al., 2013). Such punctiform pattern of AQP4 distribution was detected in immunolabeled cells (Fig. $1 B$ ) and in cells expressing recombinant AQP4e isoform (Fig. $1 F, G$ ). To learn about the size of MiDs that are present in various subcellular regions, we recorded samples with SIM and measured their diameters.

The diameter of an individual MiD was calculated as the average of two independent measurements in perpendicular directions, as indicated in Figure 1C. Distributions of MiD diameters were in the range of 120-220 nm in AQP4-immunolabeled cells (AQP4 MiDs) and 159-415 nm (AQP4e MiDs) in AQP4e transfected cells (Fig. 1D). The diameter of AQP4e MiDs was on average about half wider than that of AQP4-immunolabeled MiDs $(p<0.001$; Fig. $1 E)$, indicating that the overexpression of the AQP4e isoform affects MiD size. However, these measurements represent all cellular MiDs, since $\mathrm{AQP} 4$ antibodies target the intracellular C-terminal AQP4 epitope, and, as such, they do not discriminate between the intracellular MiDs and the OAPs resident in the plasma membrane. Similarly, the recombinant AQP4e also labeled MiDs throughout the cell. Therefore, to specifically label OAPs, the only confirmed aggregation of AQP4 in the plasma 

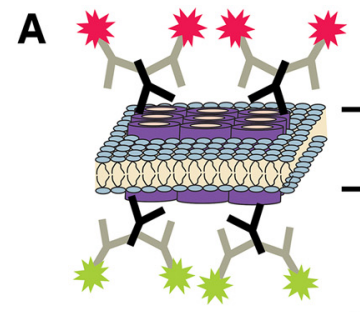

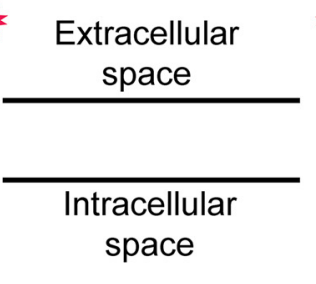

类类 Secondary $\mathrm{Ab}$
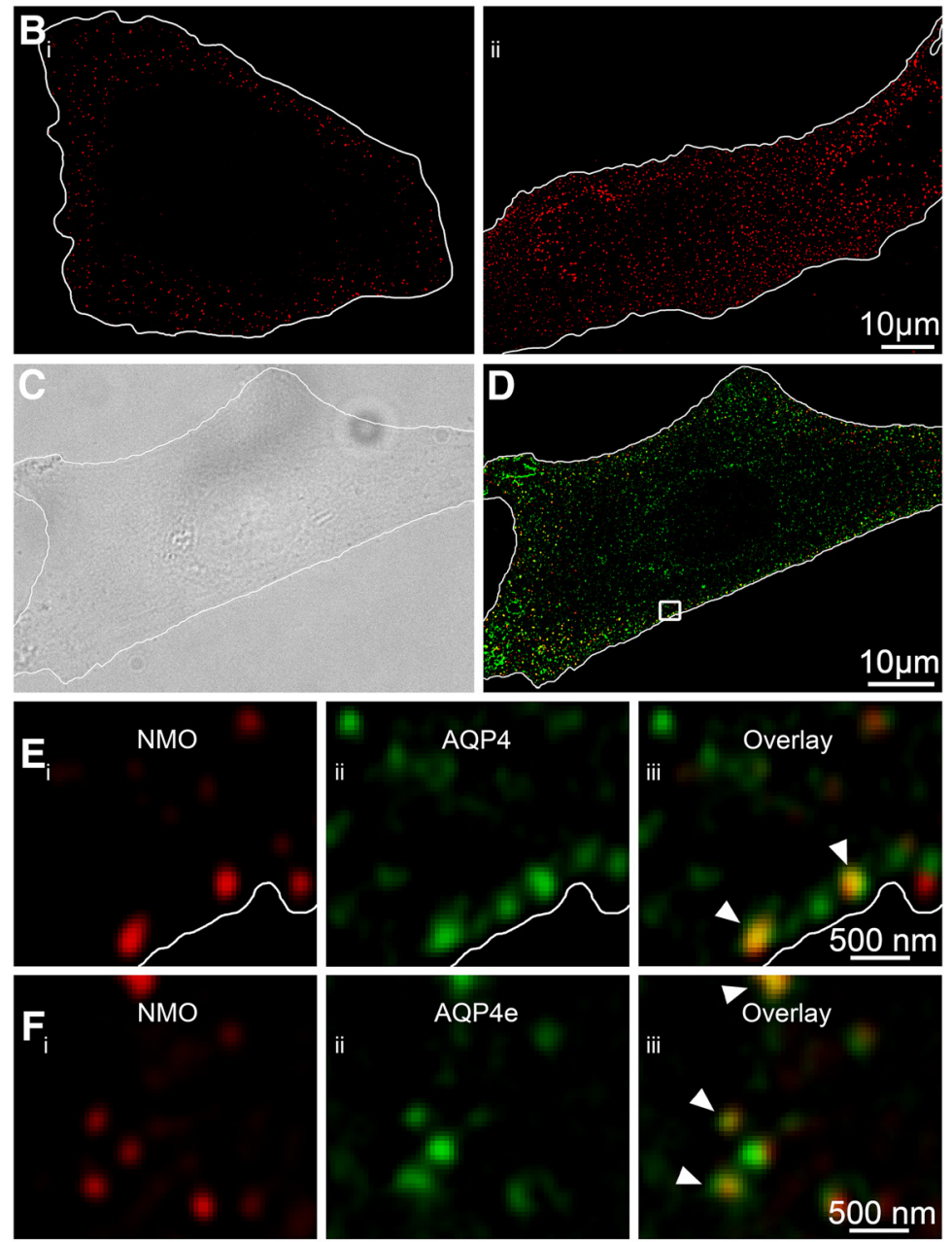

$\mathbf{G}_{\mathbf{i}}$
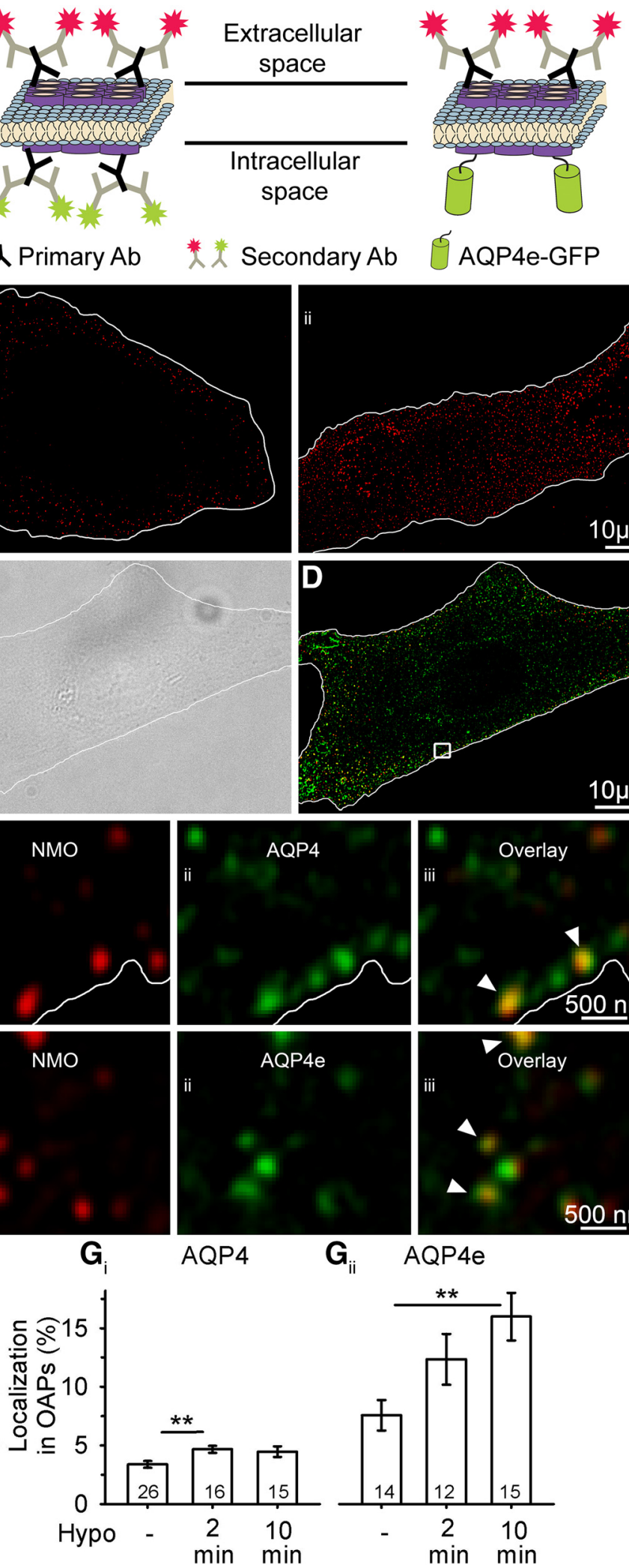

AQP4e-GFP
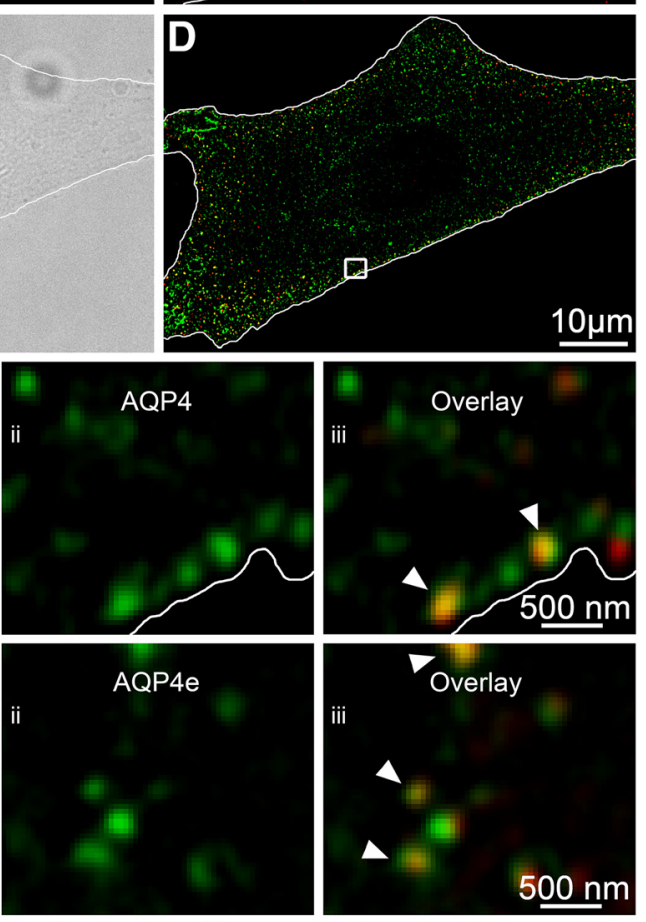

$\mathbf{G}_{\mathrm{ii}} \quad \mathrm{AQP4e}$

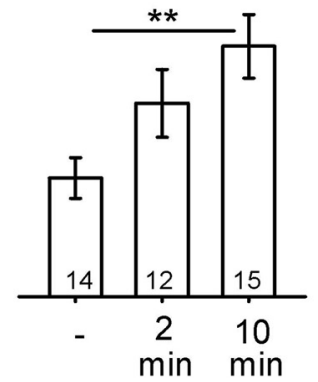

Figure 2. $A Q P 4$ e is localized in OAPs, and it promotes their formation in hypoosmotic conditions. $\boldsymbol{A}$, Schematically depicted double labeling of AQP4 channels at the plasma membrane OAPs. Primary NMO antibodies label the extracellular site of AQP4s (secondary antibodies are conjugated to a red fluorescent dye) and are thus markers of OAPs, whereas primary commercial antibodies label OAPs at the intracellular domain of the AQP4 channel (secondary antibodies are conjugated to a green fluorescent dye). Recombinant AQP4e isoforms are tagged with GFP. Of note, commercial pan antibodies also label intracellular MiDs containing AQP4s (see $\boldsymbol{E}_{i i i}$ ). $\boldsymbol{B}$, Fluorescent micrographs of astrocytes labeled with NMO primary antibodies and delineated with white lines. $\boldsymbol{B}_{\boldsymbol{i}}$ shows an equatorial plane of NMO-labeled impermeabilized astrocytes, where NMO labeling is restricted to the cell surface. We used this type of labeling to assess OAPs. $\boldsymbol{B}_{i i}$ shows an equatorial plane of NMO-labeled formaldehyde-permeabilized membrane of astrocytes (Yang et al., 1996; Rash et al., 1998), we next used the NMO antibodies, an ideal marker of the plasma membrane OAPs in cell cultures (Nicchia et al., 2009; see Materials and Methods).

AQP4e overexpression and hypoosmotic stimulation affect the abundance of OAPs Schematic depiction of dual-labeled AQP4 tetramers in OAPs is shown in Figure $2 A$. NMO-IgGs colabeled with Alexa Fluor 564 (red) tagged OAPs from the extracellular side and commercially available antiAQP4 IgGs colabeled with Alexa Fluor 488 (green) or GFP AQP4e tagged OAPs from the intracellular side, as presented in Figure 2. First, we confirmed that in our experimental conditions (labeling of nonpermeabilized cells) NMO antibodies remained close to the cell surface (Fig. $2 B_{i}$ ), therefore labeling plasma membrane OAPs. In contrast, the signal of formaldehydepermeabilized cells was pan-cellular (Fig. $2 B_{i i}$ ).

When control untransfected astrocytes were immunolabeled with commercial AQP4 IgGs (Fig. 2D,E), $3.4 \pm 0.3 \%$ of all AQP4s were detected in OAPs (Fig. 2G $G_{i}$ ). In astrocytes overexpressing the AQP4e isoform (Fig. $2 F$ ), the proportion of AQP4s in OAPs was twofold higher (Fig. $\left.2 G_{i i}\right)$. To learn whether hypoosmotic conditions trigger the redistribution of AQP4s to the plasma membrane, we repeated the experiments after 2 and $10 \mathrm{~min}$ exposures of cells to the hypoosmotic milieu (Hypo). In control untransfected cells, the percentage of OAPs (relative to all AQP4-positive puncta in the cells) increased by one-third

\section{$\leftarrow$}

astrocytes, where NMO labeling is observed also in the cytoplasm. C, DIC image of a cultured rat astrocyte. The cell is delineated with the white line. $\boldsymbol{D}$, SIM fluorescence micrograph of the same astrocyte as in $\boldsymbol{B}$, labeled as schematically shown in $\boldsymbol{A}$. The squared area is enlarged in $\boldsymbol{E}$, displaying OAPs extracellularly labeled with NMO antibodies $\left(\boldsymbol{E}_{i}\right)$, intracellularly labeled with commercial AQP4 antibodies $\left(\boldsymbol{E}_{i i}\right)$, and the overlay of both signals $\left(\boldsymbol{E}_{i i i}\right)$. The white line represents the edge of the astrocyte, as determined on the DIC image. $\boldsymbol{F}$, Section of an astrocyte showing OAPs extracellularly labeled with $\mathrm{NMO}$ antibodies $\left(\boldsymbol{F}_{i}\right)$, the intracellular signal of AQP4e-GFP $\left(\boldsymbol{F}_{i i}\right)$, and the overlay of both signals $\left(\boldsymbol{F}_{\text {iii }}\right)$. The arrowheads point to $\mathrm{CO}^{-}$ localized fluorescent signals of OAPs, labeled by NMO antibodies, that were either colabeled by AQP4 antibodies $\left(\boldsymbol{E}_{\text {iii }}\right)$ or AQP4e-GFP $\left(\boldsymbol{F}_{i i i j}\right) \cdot \boldsymbol{G}$, OAPs represented $3.4 \pm 0.3 \%$ of all antibody-labeled AQP4 microdomains in untransfected cells. Stimulation with Hypo solution increased the percentage of OAPs to $4.7 \pm 0.3 \%(2 \mathrm{~min})$ and to $4.5 \pm 0.5 \%$ (10 min), respectively $\left(\boldsymbol{G}_{\boldsymbol{i}}\right)$. Of all recombinant AQP4e-GFP MiDs in the transfected cells, $7.6 \pm 1.3 \%$ were detected in OAPs. $G_{i i}$ Stimulation with Hypo increased the percentages to $12.3 \pm 2.2 \%$ ( $2 \mathrm{~min}$ ) and to $15.9 \pm 2.0 \%$ (10 $\mathrm{min})$. Numbers in the bars denote the number of cells analyzed. ${ }^{* *} p<0.01$. 
after a 2 min exposure to Hypo $(p=$ 0.009; ANOVA followed by the Holm-Sidak method) and remained high after the $10 \mathrm{~min}$ exposure to Hypo (4.5 $\pm 0.5 \%$; $p=0.712$; Fig. $2 G_{i}$ ). In astrocytes overexpressing the AQP4e isoform, the abundance of OAPs increased by half after 2 $\mathrm{min}$ and by twofold after $10 \mathrm{~min}$ of exposure to Hypo versus control AQP4e transfected cells in isoosmotic conditions $(p=$ 0.002; ANOVA followed by the Holm-Sidak method; Fig. $2 G_{i i}$ ).

These results show that AQP4e is detected in NMO-IgG-labeled OAPs, that the hypoosmotic milieu increases the proportion of AQP4s in OAPs, and that the overexpression of the AQP4e isoform further enhances the localization of OAPs at the plasma membrane.

\section{OAPs are enlarged after hypoosmotic stimulation}

Next, we asked whether the unitary OAP size is affected in hypoosmotic conditions. The measurements of OAP diameters were performed in the same way as the measurements of MiDs (Fig. 1C). A 2 min exposure to Hypo did not affect OAP diameters either in untransfected cells or in AQP4e-overexpressing cells. On the other hand, a 10 min exposure to Hypo resulted in a statistically significant enlargement in OAP diameters versus isoosmotic controls in untransfected cells (by $\sim 10 \%$ ) and in AQP4e-overexpressing cells (by $\sim 2.5 \%$; $p<0.05$, oneway ANOVA on ranks followed by Dunn's method; Fig. $3 A_{i}, B_{i}$ ).

Although the hypoosmotic conditions can affect the OAP size, this may involve changes in the OAP AQP4 content as a result of the redistribution of individual AQP4s. Therefore, we analyzed the fluorescence intensity, a measure of the abundance of AQP4 molecules within the labeled OAPs. In untransfected cells, the average fluorescence intensity decreased statistically significantly by one-fifth after 10 min of exposure to Hypo versus control ( $p<0.05$, one-way ANOVA on ranks followed by Dunn's method; Fig. $\left.3 A_{i i}\right)$. In contrast, in AQP4e-overexpressing cells, the fluorescence intensity of OAPs transiently decreased statistically significantly after 2 min versus control (26\%), and after 10 min returned practically to the control level ( $p<0.05$, one-way ANOVA on ranks followed by Dunn's method; Fig. $3 B_{i i}$ ). Then, we measured the ratio between the average fluorescence intensity of OAPs and OAP diameter (Fig. 3C) to learn about the density of AQP4 molecules per individual OAP. If we consider that the binding of antibodies to epitopes is constant, then this ratio represents the density of AQP4 molecules in OAPs. Following the Hypo stimulation, the observed trends of AQP4 density in OAPs were similar to the trends of fluorescence intensity, for AQP4 molecules and the AQP4e isoform. The density of AQP4 in OAPs decreased significantly by $7 \%$ and by $32 \%$ after 2 and 10 min of Hypo, respectively (Fig. $3 C_{i}$ ). On the other hand, the density of AQP4e in OAPs transiently decreased by $25 \%$ after 2 min of Hypo and subsequently increased to near control value after $10 \mathrm{~min}$ (Fig. $3 C_{i i}$ ).

To summarize, a hypoosmotic milieu triggers the enlargement of OAP diameters followed by a delay. Differences in the increase of the average OAP diameter were smaller when we overexpressed AQP4e. Changes in the diameter with concomitant changes in the fluorescence intensity and density of molecules in OAPs in altered osmotic conditions indicate a structural reorganization of OAPs. The density of immunolabeled AQP4 and the density of the AQP4e isoform in OAPs changed versus prehypoosmotic conditions, indicating that the insertion/retraction and redistribution of the AQP4 molecules occurred.

\section{Cell volume changes in hypoosmotic conditions}

In general, cells respond to hypoosmotic conditions by rapid swelling followed by an adaptive response, termed RVD, which tends to recover the normal cell volume (Pasantes-Morales et al., 2006). It has been reported that AQP4 channels mediate fastswelling kinetics, which plays a crucial role in triggering RVD in astrocytes (Mola et al., 2016). For example, in wild-type (WT) mouse astrocytes, in which only the presence of AQP4a (M1) and AQP4c (M23) was assessed, the time constant of cell swelling was shorter, and the kinetics of the RVD phase was faster with a larger compensation amplitude in comparison with the astrocyte cell line devoid of AQP4 (Mola et al., 2016).

However, it is unknown whether the recently described AQP4e isoform $(\mathrm{Mz})$ is also involved in the regulation of cell volume. Therefore, we performed experiments to check whether AQP4e affects the astrocyte-swelling kinetics and RVD. Untransfected astrocytes and astrocytes overexpressing AQP4e were labeled with SR101 cytosolic dye (Fig. 4A) and exposed to hypoosmotic conditions. Cells overexpressing AQP4e exhibited faster cell swelling, observed as SR101 fluorescence intensity changes, com- 
A
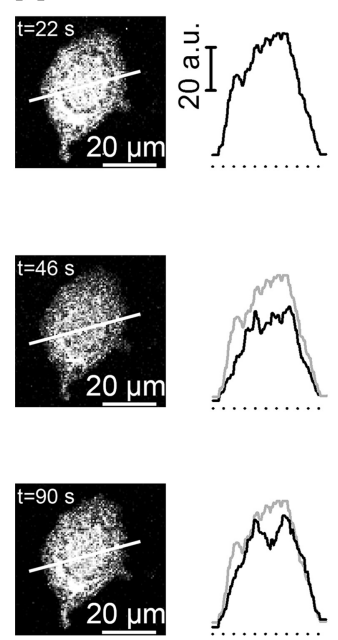

$20 \mu \mathrm{m}$
B
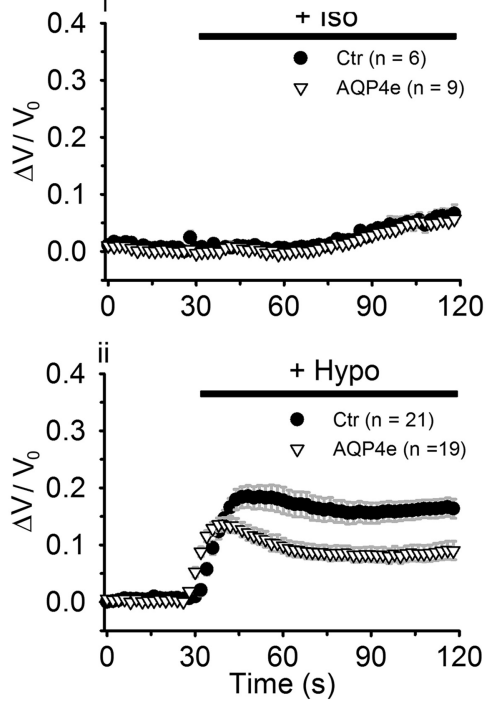

C

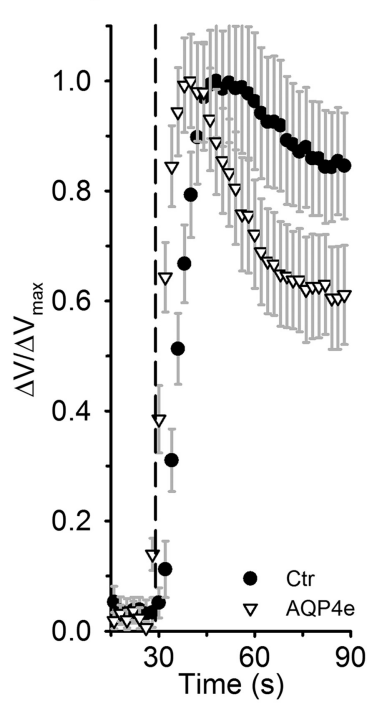

$D_{\text {i }}$

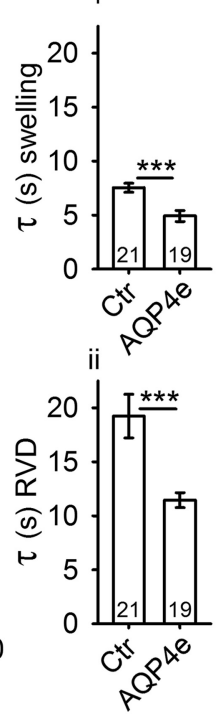

E
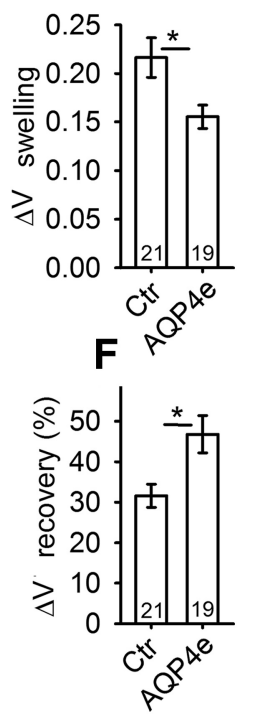

Figure 4. Astrocytes overexpressing AQP4e exhibit a faster but smaller increase in cell volume in hypoosmotic conditions. $A$, An astrocyte labeled by $S R 101$, before $(t=22 \mathrm{~s})$ and after stimulation with hypotonic milieu (at $t=46 \mathrm{~s}$ and $t=90 \mathrm{~s}$, respectively). Graphs adjacent to the micrographs represent fluorescence intensity profiles obtained along the line denoted in respective micrographs. Gray line represents fluorescence intensity profile at $t=22 \mathrm{~s}$. $\boldsymbol{B}$. The relative volume changes, obtained by measuring the average fluorescence intensity of SR101 of the whole cell, in control untransfected (Ctr) and in AQP4e-overexpressing (AQP4e) astrocytes in isoosmotic (Iso; $\boldsymbol{B}_{\boldsymbol{i}}$ ) and Hypo conditions $\left(\boldsymbol{B}_{i i}\right)$. $\boldsymbol{C}$, Normalized time-dependent changes in the volume shown in $\boldsymbol{B}_{i i}$, $\boldsymbol{B}_{i j}, \boldsymbol{C}$, Note the smaller peak of the response (i.e., swelling; $\boldsymbol{B}_{i i}$ ) and the better recovery (of the cell volume in RVD) in cells overexpressing $A Q P 4$ e compared with untransfected controls ( $\boldsymbol{C}$ ). The kinetics of the volume change was faster in cells overexpressing AQP4e. The dashed line represents the application of hypotonic solution. $\boldsymbol{D}$, Time constants (in seconds) of the swelling phase ( $\boldsymbol{D}_{\boldsymbol{i}}$ ) were on average significantly smaller in cells overexpressing AQP4e $(4.9 \pm 0.5)$ than in control untransfected cells $(7.5 \pm 0.4)$. The RVD phase $\left(\boldsymbol{D}_{i j}\right)$ occurred faster in transfected cells (11.4 \pm 0.7$)$ than in control untransfected cells (19.2 \pm 2.0 ). $\boldsymbol{E}$, Maximal amplitude of the volume increase ( $\Delta$ V swelling) was smaller in cells overexpressing AQP4e (0.16 $\pm 0.01 \mathrm{~A} . U$.) than in controls ( $0.22 \pm 0.02 \mathrm{~A} . \mathrm{U} . ; \mathrm{p}=$ 0.02). $\boldsymbol{F}$, Recovery of the cell volume in the RVD phase was higher in cells overexpressing AQP4e (Ctr, $31.6 \pm 2.8 \% ; A Q P 4 e, 46.8 \pm 4.6 \% ; p=0.02)$. Numbers in the bars or brackets represent the number of cells analyzed. Student's $t$ test was used for statistical comparison: ${ }^{*} p<0.05{ }^{* * *} p<0.001$.

pared with untransfected astrocytes (Fig. $4 B_{i i}, C$ ), whereas the addition of an isoosmotic solution did not elicit any volume change (Fig. $4 B_{i}$ ). After the addition of Hypo, the cell-swelling kinetics was $\sim 50 \%$ faster in cells overexpressing AQP4e compared with untransfected controls (Fig. $4 D_{i} ; p<0.001$ ), and the overall cell swelling was approximately one-third smaller than in untransfected controls (Fig. $4 E ; p<0.05$ ). In addition, the RVD kinetics was almost twice as fast in cells overexpressing AQP4e compared with untransfected cells (Fig. $4 D_{i i} ; p<0.001$ ), and the recovery of the cell volume in the RVD phase was much more efficient $(50 \%$ better) in AQP4e-overexpressing cells (Fig. 4F; $p<0.05$ ).

As seen in Figure 4, the basal cell volume was not completely restored by RVD within a couple of minutes. We therefore measured the changes in cell volume for an extended time period (21 min) in persisting hypoosmotic stimulation. Because fluorescent dyes are prone to bleaching, we used another super-resolution technique, AFM. In hypoosmotic conditions, a steady, slow, time-dependent increase in cell volume was observed, reaching $\sim 8.5 \%$ increase after 21 min of recording in untransfected and AQP4e-overexpressing cells in comparison with cells in normosmotic conditions (Fig. 5B). These results indicate that the capacity to contain long-term hypotonic swelling of astrocytes is limited and independent of the overexpression of the AQP4e isoform.

\section{Discussion}

In this study, we assessed the effect of the newly described waterconductive AQP4e isoform on the abundance and size of AQP4 microdomains in cultured rat astrocytes, with the focus on the clusters of AQP4 molecules resident in the plasma membrane, termed OAPs. Specifically, we measured OAP dynamics in isoosmotic and brain edema mimicking hypoosmotic conditions to- gether with the changes in cell volume. The results revealed for the first time that AQP4e participates in rapid, short-term volume regulation of astrocytes with dynamic restructuring of OAPs.

\section{AQP4e isoform localizes in OAPs in astrocytes}

Biochemical assays on HeLa cells and human glioblastoma-astrocytoma cells (Rossi et al., 2011) revealed that AQP4e likely incorporates into higher-order structures that resemble OAPs in size (Sorbo et al., 2008; Strand et al., 2009; Rossi et al., 2011). Neither of these cell types expresses AQP4 endogenously, and both were cotransfected with AQP4a, AQP4c, and AQP4e to study OAP composition in the cell lysates. The AQP4e isoform was reported to be localized largely at the plasma membrane of single cultured astrocytes (Moe et al., 2008; Sorbo et al., 2008; Rossi et al., 2011; Potokar et al., 2013). However, its plasma membrane distribution in detail was not known. In our study, the results revealed for the first time, using NMO-IgG labeling, that AQP4e also targets OAPs in rat primary astrocytes that natively express several AQP4 isoforms.

Recently, a model that predicts OAP formation was proposed. However, it takes into account only two AQP4 isoforms, predicting that the AQP4c isoform probably forms the core of the OAP, stabilizing the OAP through its $\mathrm{N}$-terminal associations, while AQP4a is preferentially localized at its periphery (Mitsuma et al., 2010; Jin et al., 2011; Rossi et al., 2012a). Additionally, it was shown that, in U87MG cells, which natively do not express AQP4, AQP4e associates with OAPs, similar to AQP4a in conditions when these cells coexpress AQP4c (M23; Rossi et al., 2011). Our results now show directly in a cell natively expressing AQP4e that this is taking place. Therefore, an upgrade of the OAP formation model should also take into account the assembly of AQP4e into 

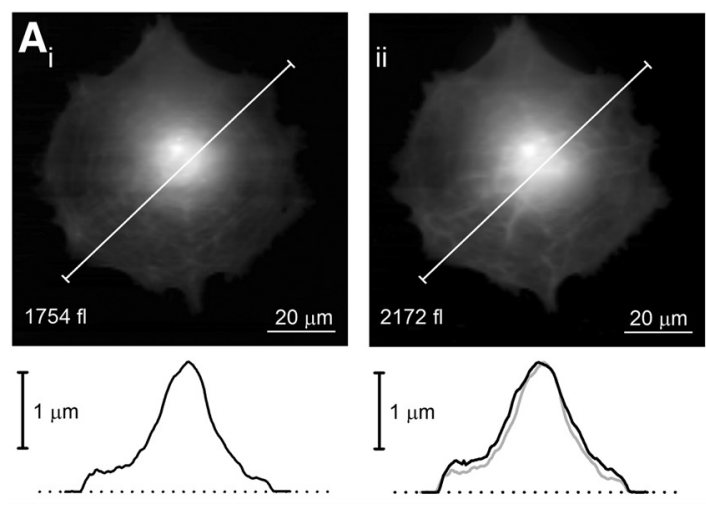
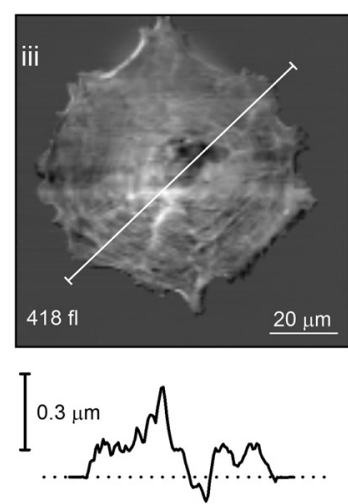

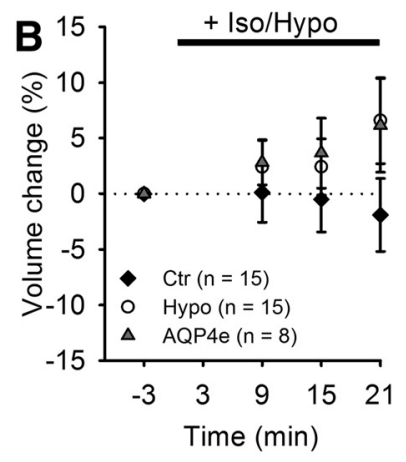

Figure 5. Prolonged hypoosmotic stimulation induces a slow increase in astrocyte volume monitored by AFM. $\boldsymbol{A}_{\boldsymbol{i}}, \boldsymbol{A}_{i j}$, Linearized height images of an astrocyte before $\left(\boldsymbol{A}_{i}\right)$ and 21 min after $\left(\boldsymbol{A}_{i j}\right)$ the application of a hypotonic solution and corresponding height profiles. $\boldsymbol{A}_{i i i}$, A subtraction image (hypotonic - control) indicating cell swelling. $\boldsymbol{B}$, Time-dependent changes in the total cell volume of astrocytes treated in isoosomotic solution (controls, black diamonds) or in hypotonic solution (empty circles), and astrocytes transfected with AQP4e and treated with hypotonic milieu (gray triangles). Numbers in the brackets represent the number of cells analyzed. One-way ANOVA with the Holm-Sidak post hoc test versus control was used for statistical comparison.

OAPs and predict its role in the formation of OAPs. This is consistent with the present results where the overexpression of AQP4e clearly affects the abundance of OAPs in astrocytes.

In addition to OAPs that resemble a general plasmalemmal structural cluster of AQP4, in cultured astrocytes a significant intracellular pool of AQP4 is present, compared with the modest intracellular pool observed in the perfusion-fixed brain (Nielsen et al., 1997; Nicchia et al., 2008; Potokar et al., 2013). This intracellular pool is observed as a punctiform pattern, resembling vesicles. The size of such intracellular puncta or MiDs has not been determined before. The present study revealed their diameters. MiD diameters from all cellular MiDs, comprising intracellular AQP4 clusters and plasmalemmal OAPs, showed large variability between the endogenous MiDs $(166 \pm 1 \mathrm{~nm})$ and AQP4e-overexpressing MiDs $(237 \pm 1 \mathrm{~nm})$. Intracellular MiDs containing endogenous AQP4 and intracellular MiDs with the recombinant AQP4e are likely localized in the secretory and degradation subcellular compartments, in which the overexpression of AQP4e affects their size (Madrid et al., 2001; Moe et al., 2008; Potokar et al., 2013). On the other hand, the diameters of endogenous OAPs were similar to the diameters of OAPs that were overexpressing AQP4e. Endogenous $(188 \pm 1 \mathrm{~nm})$ and AQP4e-overexpressing OAPs $(183 \pm 1 \mathrm{~nm})$ are generally in line with the OAP diameters measured in adult rat astrocyte cultures $(150-500 \mathrm{~nm})$ as imaged by total internal reflection fluorescence microscopy (Nicchia et al., 2009, 2010). Further, the OAP diameters recorded in this study are also in line with the measurements obtained by other super-resolution microscopy techniques (direct stochastic optical reconstruction microscopy and photo-activated localization microscopy), where they were $\sim 100 \mathrm{~nm}$ when expressing recombinant AQP4 isoforms (Rossi et al., 2012a). Some discrepancies with our results can be explained by the fact that OAPs are diverse in size, shape, and substructure and are subject to constant rearrangement in live cells (Sorbo et al., 2008). Diversity in the dynamics and size of OAPs can also be affected by the extracellular milieu, as we considered further in this study.

\section{AQP4e affects the cell abundance of OAPs in hypoosmotic conditions}

It was proposed for AQP4e that, like AQP4a, it may act as an accessory isoform, regulating OAP assembly, whereas AQP4c represents the core of OAP (Suzuki et al., 2008; Crane and Verkman, 2009; Strand et al., 2009; Mitsuma et al., 2010; Tajima et al., 2010; Jin et
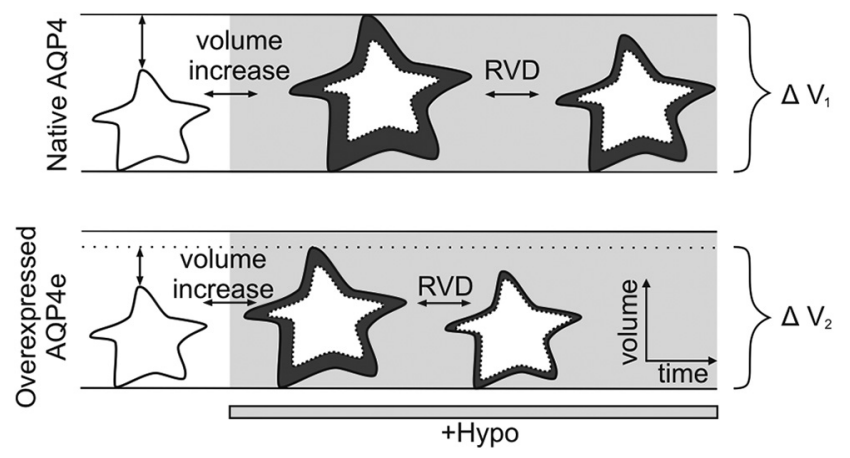

Figure 6. A schematic drawing of rapid AQP4e-dependent changes in cell swelling and RVD in astrocytes. Astrocytes in hypoosmotic conditions (marked by light gray) respond by rapid swelling and by subsequent RVD, both of which are faster in cells overexpressing AQP4e. The maximal volume increase at the end of the swelling phase is smaller in cells overexpressing $\mathrm{AQP} 4 \mathrm{e}$ compared with nontransfected cells ( $\Delta \mathrm{V} 2<\Delta \mathrm{V} 1$; changes in cell volume in different phases can also be observed by comparing the cell area in dark gray compared with the initial cell volume in white). In addition, the recovery of the cell volume during the RVD phase was higher in cells overexpressing AQP4e compared with nontransfected cells.

al., 2011; Rossi et al., 2011). Here, we confirmed this hypothesis, as the results revealed that $\mathrm{AQP} 4 \mathrm{e}$ affects $\mathrm{OAP}$ dynamics in primary astrocytes natively expressing all known water-permeable plasma membrane AQP4 isoforms. Namely, the overexpression of AQP4e resulted in a higher abundance of OAPs, an effect that was even more pronounced in hypoosmotic conditions. It appears that AQP4e contributes to the assembly of new OAPs and/or to the redistribution of existing OAPs, consistent with reports of the reorganization and slow mobility of OAPs (Rossi et al., 2012a).

In U87MG cells, it was shown that OAP size can be affected by different expression ratios of AQP4a (M1), AQP4c (M23), and $\mathrm{AQP} 4 \mathrm{e}(\mathrm{Mz})$ isoforms. For example, at a higher ratio of AQP4a to AQP4c, OAPs were smaller (Tajima et al., 2010; Jin et al., 2011). This effect was attributed to AQP4a, which was proposed to block the association of tetramers through coating of the outer surface of OAPs (Tajima et al., 2010). Overexpression of AQP4e increased the average OAP size only modestly (by 4\%). This finding suggests that although AQP4a and AQP4e are speculated to regulate OAP assembly in a similar manner (Furman et al., 2003; Strand et al., 2009; Rossi et al., 2011, 2012a), they may in fact have different roles. Whereas AQP4a was shown to affect OAP size more, AQP4e appears to primarily affect OAP reorganization and assembly of new OAPs, especially in hypoosmotic conditions. 
Moreover, the results revealed that, in the hypoosmotic milieu, the density of immunolabeled AQP4 molecules and the density of recombinant $\mathrm{AQP} 4 \mathrm{e}$ isoforms are altered in individual OAPs. However, it is presently unclear and needs further consideration whether this process is the consequence of altered ratios of respective AQP4 isoforms or the reorganization of existing molecules in OAPs.

\section{The role of AQP4e in regulatory volume decrease}

AQPs play a key role in astrocyte volume changes, as has been demonstrated by several studies [i.e., by knocking down AQP4 channels or by the expression of AQP4a (M1) and AQP4c (M23) isoforms in cells that do not natively express AQP4; Mitsuma et al., 2010; Benfenati et al., 2011; Mola et al., 2016]. For example, it has been reported that mouse astrocytes lacking AQP4 (AQP4 $\mathrm{KO}$ astrocytes) show slower kinetics in cell swelling than WT mouse astrocytes (Mola et al., 2016). Moreover, the expression of $\mathrm{AQP} 4 \mathrm{c}(\mathrm{M} 23)$, the core OAP isoform, and the AQP4a (M1) isoform in the TNC1 astrocyte line reduced the cell-swelling kinetics in hypoosmotic conditions severalfold (Benfenati et al., 2011; Mola et al., 2016). In agreement, our data, highlighting the role of $\mathrm{AQP} 4 \mathrm{e}$ in cell-swelling kinetics, show that overexpression of the $\mathrm{AQP} 4 \mathrm{e}$ isoform triggers faster cell-swelling versus untransfected astrocytes. We observed smaller potentiation of cell-swelling kinetics versus untransfected cells, compared with results published previously (Benfenati et al., 2011; Mola et al., 2016). This difference may arise from the fact that DI TNC1 astrocytes natively do not express AQP4 channels. The maximal cell volume changes were smaller in AQP4e-overexpressing cells when compared with AQP4a (M1)-expressing D1TNC cells, but were similar to those in AQP4c (M23)-expressing D1TNC cells, as reported previously (Benfenati et al., 2011).

In our experiments, the swelling phase in untransfected and in AQP4e-overexpressing astrocytes was immediately followed by an RVD phase, as observed previously (Benfenati et al., 2011; Mola et al., 2016). The RVD phase observed by Mola et al. (2016) was at least twice as fast in WT astrocytes as in AQP4 KO astrocytes as well as in the DI TNC1 astrocyte line expressing AQP4c (M23) compared with AQP4 KO lines, and had a larger amplitude. Similarly, the RVD phase in AQP4e-overexpressing astrocytes in our experiments was approximately twofold faster than in untransfected cells. Mola et al. (2016) showed that even after $\sim 1$ min of hypoosmotic stimulation, the cell volume did not return to the basal level. Moreover, a steady increase in astrocyte volume after prolonged hypoosmotic stimulation was reported (Pangrsic et al., 2006; Hirrlinger et al., 2008). Our data support this notion; in astrocytes exposed to hypotonicity for $21 \mathrm{~min}$, a slow and steady increase in cell volume was recorded that was present in untransfected and AQP4e-overexpressing astrocytes. Discrepancies in the extent of cell swelling between these data and previously published data may arise from the different methods used for cell volume determination, as well as from measurements at different cell parts; we here measured the total cell volume. Namely, cross-sectional area measurements of astrocyte soma yielded $\sim 20-$ $40 \%$ increase in cultured cells after 200 s of hypoosmotic stimulation (Pangrsic et al., 2006). Similarly, a substantial increase in soma areas in tissue slices was observed after $30 \mathrm{~min}$, whereas astrocyte processes did not swell (Hirrlinger et al., 2008).

In conclusion, this study provides new insights into the role of $\mathrm{AQP} 4 \mathrm{e}$ in OAP assembly and cell volume regulation of astrocytes (the latter is summarized in Fig. 6).

\section{References}

Agre P, Brown D, Nielsen S (1995) Aquaporin water channels: unanswered questions and unresolved controversies. Curr Opin Cell Biol 7:472-483. CrossRef Medline

Badaut J, Fukuda AM, Jullienne A, Petry KG (2014) Aquaporin and brain diseases. Biochim Biophys Acta 1840:1554-1565. CrossRef Medline

Benfenati V, Caprini M, Dovizio M, Mylonakou MN, Ferroni S, Ottersen OP, Amiry-Moghaddam M (2011) An aquaporin-4/transient receptor potential vanilloid 4 (AQP4/TRPV4) complex is essential for cell-volume control in astrocytes. Proc Natl Acad Sci U S A 108:2563-2568. CrossRef Medline

Cheng A, van Hoek AN, Yeager M, Verkman AS, Mitra AK (1997) Threedimensional organization of a human water channel. Nature 387:627630. CrossRef Medline

Crane JM, Verkman AS (2009) Determinants of aquaporin-4 assembly in orthogonal arrays revealed by live-cell single-molecule fluorescence imaging. J Cell Sci 122:813-821. CrossRef Medline

Crane JM, Tajima M, Verkman AS (2010) Live-cell imaging of aquaporin-4 diffusion and interactions in orthogonal arrays of particles. Neuroscience 168:892-902. CrossRef Medline

Frigeri A, Gropper MA, Umenishi F, Kawashima M, Brown D, Verkman AS (1995) Localization of MIWC and GLIP water channel homologs in neuromuscular, epithelial and glandular tissues. J Cell Sci 108:2993-3002. Medline

Furman CS, Gorelick-Feldman DA, Davidson KG, Yasumura T, Neely JD, Agre P, Rash JE (2003) Aquaporin-4 square array assembly: opposing actions of M1 and M23 isoforms. Proc Natl Acad Sci U S A 100:1360913614. CrossRef Medline

Haj-Yasein NN, Vindedal GF, Eilert-Olsen M, Gundersen GA, Skare Ø, Laake P, Klungland A, Thorén AE, Burkhardt JM, Ottersen OP, Nagelhus EA (2011) Glial-conditional deletion of aquaporin-4 (Aqp4) reduces bloodbrain water uptake and confers barrier function on perivascular astrocyte endfeet. Proc Natl Acad Sci U S A 108:17815-17820. CrossRef Medline

Hasegawa H, Ma T, Skach W, Matthay MA, Verkman AS (1994) Molecular cloning of a mercurial-insensitive water channel expressed in selected water-transporting tissues. J Biol Chem 269:5497-5500. Medline

Hiroaki Y, Tani K, Kamegawa A, Gyobu N, Nishikawa K, Suzuki H, Walz T, Sasaki S, Mitsuoka K, Kimura K, Mizoguchi A, Fujiyoshi Y (2006) Implications of the aquaporin- 4 structure on array formation and cell adhesion. J Mol Biol 355:628-639. CrossRef Medline

Hirrlinger PG, Wurm A, Hirrlinger J, Bringmann A, Reichenbach A (2008) Osmotic swelling characteristics of glial cells in the murine hippocampus, cerebellum, and retina in situ. J Neurochem 105:1405-1417. CrossRef Medline

Hutter JL, Bechhoefer J (1993) Calibration of atomic-force microscope tips. Rev Sci Instrum 64:1868-1873. CrossRef

Iorio R, Fryer JP, Hinson SR, Fallier-Becker P, Wolburg H, Pittock SJ, Lennon VA (2013) Astrocytic autoantibody of neuromyelitis optica (NMO$\operatorname{IgG}$ ) binds to aquaporin-4 extracellular loops, monomers, tetramers and high order arrays. J Autoimmun 40:21-27. CrossRef Medline

Jin BJ, Rossi A, Verkman AS (2011) Model of aquaporin-4 supramolecular assembly in orthogonal arrays based on heterotetrameric association of M1-M23 isoforms. Biophys J 100:2936-2945. CrossRef Medline

Jung JS, Bhat RV, Preston GM, Guggino WB, Baraban JM, Agre P (1994) Molecular characterization of an aquaporin cDNA from brain: candidate osmoreceptor and regulator of water balance. Proc Natl Acad Sci U S A 91:13052-13056. CrossRef Medline

King LS, Kozono D, Agre P (2004) From structure to disease: the evolving tale of aquaporin biology. Nat Rev Mol Cell Biol 5:687-698. CrossRef Medline

Lennon VA, Wingerchuk DM, Kryzer TJ, Pittock SJ, Lucchinetti CF, Fujihara K, Nakashima I, Weinshenker BG (2004) A serum autoantibody marker of neuromyelitis optica: distinction from multiple sclerosis. Lancet 364: 2106-2112. CrossRef Medline

Lennon VA, Kryzer TJ, Pittock SJ, Verkman AS, Hinson SR (2005) IgG marker of optic-spinal multiple sclerosis binds to the aquaporin-4 water channel. J Exp Med 202:473-477. CrossRef Medline

Madrid R, Le Maout S, Barrault MB, Janvier K, Benichou S, Mérot J (2001) Polarized trafficking and surface expression of the AQP4 water channel are coordinated by serial and regulated interactions with different clathrin-adaptor complexes. EMBO J 20:7008-7021. CrossRef Medline

Manley GT, Fujimura M, Ma T, Noshita N, Filiz F, Bollen AW, Chan P, 
Verkman AS (2000) Aquaporin-4 deletion in mice reduces brain edema after acute water intoxication and ischemic stroke. Nat Med 6:159-163. CrossRef Medline

Mitsuma T, Tani K, Hiroaki Y, Kamegawa A, Suzuki H, Hibino H, Kurachi Y, FujiyoshiY (2010) Influence of the cytoplasmic domains of aquaporin-4 on water conduction and array formation. J Mol Biol 402:669-681. CrossRef Medline

Moe SE, Sorbo JG, Sogaard R, Zeuthen T, Petter Ottersen O, Holen T (2008) New isoforms of rat Aquaporin-4. Genomics 91:367-377. CrossRef Medline

Mola MG, Sparaneo A, Gargano CD, Spray DC, Svelto M, Frigeri A, Scemes E, Nicchia GP (2016) The speed of swelling kinetics modulates cell volume regulation and calcium signaling in astrocytes: a different point of view on the role of aquaporins. Glia 64:139-154. CrossRef Medline

Nagelhus EA, Ottersen OP (2013) Physiological roles of aquaporin-4 in brain. Physiol Rev 93:1543-1562. CrossRef Medline

Nagelhus EA, Mathiisen TM, Ottersen OP (2004) Aquaporin-4 in the central nervous system: cellular and subcellular distribution and coexpression with KIR4.1. Neuroscience 129:905-913. CrossRef Medline

Nase G, Helm PJ, Enger R, Ottersen OP (2008) Water entry into astrocytes during brain edema formation. Glia 56:895-902. CrossRef Medline

Nečas D, Klapetek P (2012) Gwyddion: an open-source software for SPM data analysis. Central Eur J Phys 10:181-188.

Nicchia GP, Rossi A, Mola MG, Procino G, Frigeri A, Svelto M (2008) Actin cytoskeleton remodeling governs aquaporin-4 localization in astrocytes. Glia 56:1755-1766. CrossRef Medline

Nicchia GP, Mastrototaro M, Rossi A, Pisani F, Tortorella C, Ruggieri M, Lia A, Trojano M, Frigeri A, Svelto M (2009) Aquaporin-4 orthogonal arrays of particles are the target for neuromyelitis optica autoantibodies. Glia 57:1363-1373. CrossRef Medline

Nicchia GP, Rossi A, Mola MG, Pisani F, Stigliano C, Basco D, Mastrototaro M, Svelto M, Frigeri A (2010) Higher order structure of aquaporin-4. Neuroscience 168:903-914. CrossRef Medline

Nielsen S, Nagelhus EA, Amiry-Moghaddam M, Bourque C, Agre P, Ottersen OP (1997) Specialized membrane domains for water transport in glial cells: high-resolution immunogold cytochemistry of aquaporin-4 in rat brain. J Neurosci 17:171-180. Medline

Pangrsic T, Potokar M, Haydon PG, Zorec R, Kreft M (2006) Astrocyte swelling leads to membrane unfolding, not membrane insertion. J Neurochem 99:514-523. CrossRef Medline

Papadopoulos MC, Manley GT, Krishna S, Verkman AS (2004) Aquaporin-4 facilitates reabsorption of excess fluid in vasogenic brain edema. FASEB J 18:1291-1293. CrossRef Medline

Pasantes-Morales H, Lezama RA, Ramos-Mandujano G, Tuz KL (2006) Mechanisms of cell volume regulation in hypo-osmolality. Am J Med 119:S4-S11. CrossRef Medline

Potokar M, Stenovec M, Kreft M, Kreft ME, Zorec R (2008) Stimulation inhibits the mobility of recycling peptidergic vesicles in astrocytes. Glia 56:135-144. CrossRef Medline

Potokar M, Stenovec M, Jorgačevski J, Holen T, Kreft M, Ottersen OP, Zorec R (2013) Regulation of AQP4 surface expression via vesicle mobility in astrocytes. Glia 61:917-928. CrossRef Medline

Rash JE, Yasumura T, Hudson CS, Agre P, Nielsen S (1998) Direct immunogold labeling of aquaporin- 4 in square arrays of astrocyte and ependy- mocyte plasma membranes in rat brain and spinal cord. Proc Natl Acad Sci U S A 95:11981-11986. CrossRef Medline

Ratelade J, Bennett JL, Verkman AS (2011) Evidence against cellular internalization in vivo of NMO-IgG, aquaporin-4, and excitatory amino acid transporter 2 in neuromyelitis optica. J Biol Chem 286:45156-45164. CrossRef Medline

Rossi A, Crane JM, Verkman AS (2011) Aquaporin-4 Mz isoform: brain expression, supramolecular assembly and neuromyelitis optica antibody binding. Glia 59:1056-1063. CrossRef Medline

Rossi A, Moritz TJ, Ratelade J, Verkman AS (2012a) Super-resolution imaging of aquaporin- 4 orthogonal arrays of particles in cell membranes. J Cell Sci 125:4405-4412. CrossRef Medline

Rossi A, Ratelade J, Papadopoulos MC, Bennett JL, Verkman AS (2012b) Consequences of NMO-IgG binding to aquaporin-4 in neuromyelitis optica. Proc Natl Acad Sci U S A 109:E1511. CrossRef Medline

Sorbo JG, Moe SE, Ottersen OP, Holen T (2008) The molecular composition of square arrays. Biochemistry 47:2631-2637. CrossRef Medline

Sørbø JG, Fleckenstein B, Ottersen OP, Holen T (2012) Small-scale purification and mass spectrometry analysis reveal a third aquaporin-4 protein isoform of $36 \mathrm{kDa}$ in rat brain. J Neurosci Methods 211:31-39. CrossRef Medline

Strand L, Moe SE, Solbu TT, Vaadal M, Holen T (2009) Roles of aquaporin-4 isoforms and amino acids in square array assembly. Biochemistry 48:57855793. CrossRef Medline

Suzuki H, Nishikawa K, Hiroaki Y, Fujiyoshi Y (2008) Formation of aquaporin- 4 arrays is inhibited by palmitoylation of $\mathrm{N}$-terminal cysteine residues. Biochim Biophys Acta 1778:1181-1189. CrossRef Medline

Tajima M, Crane JM, Verkman AS (2010) Aquaporin-4 (AQP4) associations and array dynamics probed by photobleaching and single-molecule analysis of green fluorescent protein-AQP4 chimeras. J Biol Chem 285: 8163-8170. CrossRef Medline

Takumi Y, Nagelhus EA, Eidet J, Matsubara A, Usami S, Shinkawa H, Nielsen S, Ottersen OP (1998) Select types of supporting cell in the inner ear express aquaporin-4 water channel protein. Eur J Neurosci 10:35843595. CrossRef Medline

Tani K, Mitsuma T, Hiroaki Y, Kamegawa A, Nishikawa K, Tanimura Y, Fujiyoshi Y (2009) Mechanism of aquaporin-4's fast and highly selective water conduction and proton exclusion. J Mol Biol 389:694-706. CrossRef Medline

Verkman AS, Binder DK, Bloch O, Auguste K, Papadopoulos MC (2006) Three distinct roles of aquaporin-4 in brain function revealed by knockout mice. Biochim Biophys Acta 1758:1085-1093. CrossRef Medline

Wolburg H, Noell S, Fallier-Becker P, Mack AF, Wolburg-Buchholz K (2012) The disturbed blood-brain barrier in human glioblastoma. Mol Aspects Med 33:579-589. CrossRef Medline

Yang B, Ma T, Verkman AS (1995) cDNA cloning, gene organization, and chromosomal localization of a human mercurial insensitive water channel. Evidence for distinct transcriptional units. J Biol Chem 270:2290722913. CrossRef Medline

Yang B, Brown D, Verkman AS (1996) The mercurial insensitive water channel (AQP-4) forms orthogonal arrays in stably transfected Chinese hamster ovary cells. J Biol Chem 271:4577-4580. CrossRef Medline 